\title{
Quality Control of First Trimester Ultrasound Examinations in the Gynecology and Obstetrics Department of the University Teaching Hospital Yalgado Ouedraogo (UTH-YO) of Ouagadougou, Burkina Faso
}

\author{
Ouattara Adama1,2*, Nde Ouédraogo Nina Astrid 1,2, Lankoandé Bako Natacha3, \\ Ouédraogo Smaila1,2, Nare Amelie'2, Tougma Sanou Aline ${ }^{3}$, Sawadogo Yobi Alexis1,2, \\ Millogo Traoré Francoise ${ }^{1,2}$, Ouédraogo Marie Charlemagne ${ }^{1,2}$, Ouédraogo Ali1,2, \\ Thieba Bonané Blandine ${ }^{1,2}$
}

\begin{abstract}
${ }^{1}$ Training and Research Unit in Health Sciences (TRU/HS), University Ouaga 1 Pr Joseph KI ZERBO, Ouagadougou, Burkina Faso ${ }^{2}$ Department of Gynecology and Obstetrics, The University Teaching Hospital Yalgado Ouedraogo of Ouagadougou (UTH-YO), Ouagadougou, Burkina Faso

${ }^{3}$ Department of Gynecology and Obstetrics, The Bogodogo University Teaching Hospital of Ouagadougou (UTH-B), Ouagadougou, Burkina Faso

Email: *ouattzangaadama@yahoo.fr
\end{abstract}

How to cite this paper: Adama, O., Astrid, N.O.N., Natacha, L.B., Smaila, O., Amelie, N., Aline, T.S., Alexis, S.Y., Francoise, M.T., Charlemagne, O.M., Ali, O. and Blandine, T.B. (2018) Quality Control of First Trimester Ultrasound Examinations in the Gynecology and Obstetrics Department of the University Teaching Hospital Yalgado Ouedraogo (UTH-YO) of Ouagadougou, Burkina Faso. Open Journal of Obstetrics and Gynecology, 8, 1399-1413. https://doi.org/10.4236/ojog.2018.813141

Received: October 7, 2018

Accepted: November 9, 2018

Published: November 12, 2018

Copyright $\odot 2018$ by authors and Scientific Research Publishing Inc. This work is licensed under the Creative Commons Attribution International License (CC BY 4.0).

http://creativecommons.org/licenses/by/4.0/

\section{Abstract}

Objective: To evaluate the quality of first trimester ultrasound examinations in patients consulting in the gynecology and obstetrics department at the University Teaching Hospital Yalgado Ouedraogo (UTH-YO) of Ouagadougou. Method: Our study took place from January 1st to March 31st 2017, in the department of Obstetrics and Gynecology of the University Teaching Hospital Yalgado Ouedraogo of Ouagadougou. This was a descriptive study on the records of the first trimester ultrasound of pregnancy, with analysis of the iconography. We used the criteria of the Technical Committee of Fetal Echography (TCFE) of France to analyse all the ultrasound reports brought by the patients. Results: Two hundred reports were collected in three months. In terms of ultrasound identification, only 2 reports out of 200 mentioned the brand and date of first circulation and 4 specified the type of device. The study of the quality of the appointment showed that only $52 \%$ of the ultrasounds had been performed at the right time, between 11SA - 14SA of amenorrhea. For the nuchal translucency quality, we rated by the Herman score, $41.67 \%$ of the scores were of "unacceptable" quality and only $58.33 \%$ were of "acceptable" quality we did not achieve "excellent" quality. The analysis of the 
biparietal diameter (BIP) cuts revealed that $1 / 4$ only anatomical cuts had been well made. Analysis of the cranio caudal length (CCL) cuts showed that only $14.58 \%$ of the CCLs had been well done. Elements of early morphology had been explored to less than 5\%. Conclusion: The results revealed the acceptable quality of the NC measurements, but a small proportion of NC achieved. The quality of the ultrasound, morphological analysis and biometrics period is not very acceptable.

\section{Keywords}

Ultrasonography, First Trimester, Reports, UTH-YO

\section{Introduction}

The performance of the first quarter morphological examination has been the subject of numerous publications with a constant annual increase for 5 years. For the sonographer, it is a question of identifying the fetuses at risk within a generally healthy population. Ultrasound from the first trimester is a powerful screening tool made available to the obstetrician [1] [2] [3] [4].

From an obvious public health perspective, it is clear that these acts should be carried out according to minimum quality criteria, in order to avoid worries, costs and additional examinations on healthy fetuses. This quality approach should also make it possible to concentrate efforts on fetuses that deserve more specific diagnostic tests. Given the large number of actors in antenatal surveillance, harmonisation of practices, especially in the context of resource-limited countries, seems justified so that each outcome can be interpreted in the same way. Sonographers themselves, faced with a heavy workload, should provide themselves with the means of self-control in order to encourage self-criticism, a guarantee of the constant improvement of medicine, which is by no means an exact science [1].

In our country, obstetrical ultrasound has experienced great growth, but the lack of control and standardization of the reports gives free rein to each operator to analyse in the fetus the elements he considers useful and to formulate his own reporting model. This could lead to many disparities in reporting. Through this study, we propose to analyze in a more detailed way the quality of first trimester ultrasound examinations of pregnancy seen in patients having consulted in the gynecology and obstetrics department of the University Teaching Hospital Yalgado Ouedraogo (UTH-YO) of Ouagadougou, Burkina Faso.

\section{Materials and Method}

Our study took place from January 1st to March 31st, 2017 in the obstetrical gynecology department of the University Hospital Yalgado OUEDRAOGO (UTH-YO). This was a cross-sectional study with descriptive purpose on the second trimester pregnancy ultrasound reports that the patient brought with them during their consultation. We did the analysis of the iconographies looking at both the 
morphologic and the biometric settings. To achieve our objectives, we conducted our study in a hospital setting, hence the choice of the UTH-YO maternity department. We were interested in all pregnant women at the consultation or in delivery and the labor room who were in possession of their second trimester ultrasound report. The calculated sample size was 140 ultrasound scans was calculated according to the formula: $\mathrm{n}=(\mathrm{Z} 1-\alpha / 2) 2 \times \mathrm{P} \times(1-\mathrm{P}) / \mathrm{i} 2$. Thus, the final size of the sample is 140 ultrasounds. To increase the power of the study, we corrected $n=200$ ultrasounds reports. The patients included in our sample met the following criteria:

- patient of childbearing age,

- patient carrying a pregnancy beyond the second trimester,

- patient seen in the department of obstetrics and gynecology during the study period,

- patient with a second trimester ultrasound of pregnancy report done by a practitioner other than those involved in the study.

We did not include in our study the ultrasounds performed on twin pregnancies as well as on stopped pregnancies. We collected the ultrasounds reports from the patients received in the Gynecology and obstetrics department after a presentation on the objectives of the study. We used a standardized collection sheet as a data collection instrument.

After the collection of the ultrasounds reports and especially the iconographies were analyzed by three people including 3 doctors holding the National Inter-University Diploma (NIUD) in gynecological and obstetrical ultrasound in France. It must be said that before the study began, the attending physicians in charge had held about ten training sessions with the entire study group. During this mini training, the different images and recommendations of the Technical Committee of Fetal Echography (TCFE) on first trimester (T1) ultrasound were the subject of extensive exchanges to put everyone on the same level. The data were captured and analyzed on a microcomputer using the Epi info software version 7.1.4.0. The tables and graphs were produced in Excel and Word 2013 (Figure 1 \& Figure 2, Table 1).

The oral informed consent of the gestants was obtained prior to the start of this investigation. To ensure confidentiality in this study, no sonographer or structure name to identify a health professional was mentioned on a data collection sheet. The data will be used exclusively to make recommendations for the harmonization of the practice for the benefit of pregnant women. We also got the approval of the Ethics Committee on Research.

We used the Herman score (Table 2 and Table 3 ) to evaluate the nuchal translucency provided in the iconography and we used the Salomon method [5]

Table 1. Interpreting Herman score results [5].

\begin{tabular}{ccccc}
\hline Interprétation & Unacceptable & Insufficient & Acceptable & Excellent \\
\hline Score & 1 ou 0 & 3 ou 2 & 7 à 4 & 9 ou 8 \\
\hline
\end{tabular}




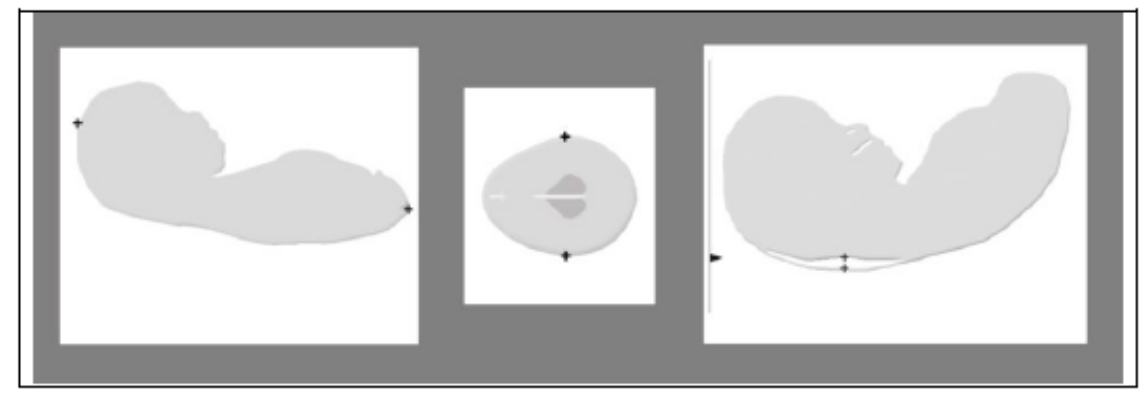

Figure 1. Obligatory image of a first trimester ultrasound according to the technical committee of fetal ultrasound [5].

\section{Critères majeurs}
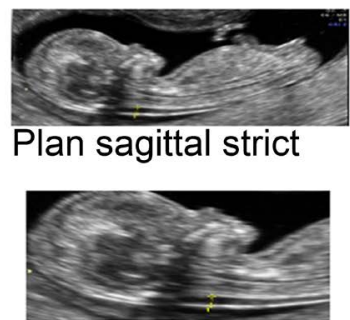

Calipers

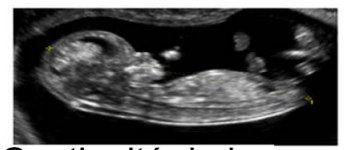

Continuité de la peau
3 Critères mineurs

2

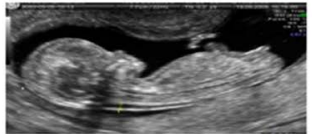

Zoom suffisant

2

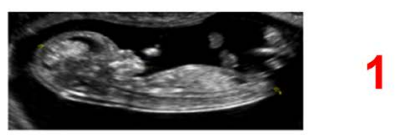

Amnios reconnu ou éloigné

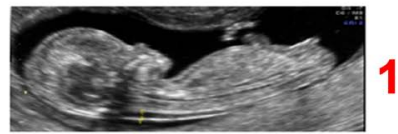

Position de la tête

Figure 2. Herman's scoring [5]. NB: critéres majeurs = major criteria, critères mineurs = minor criteria.

to evaluate the quality of the CCL and BIP. We considered acceptable control when for an item analyzed, the completion rate exceeded $50 \%$ and not very acceptable when it was less than $50 \%$.

\section{Results}

\subsection{Characteristics of the Population}

The average age of the pregnant women was 29 years with extremes of 19 and 45 years. The 25 - 29 age group was the most represented. In our study sample 3/4 of the patients came from the city of Ouagadougou. Housewives were the most represented. Also, 146 patients (73\%) reported having used a modern method of contraception. High blood pressure was the most common medical history. One in four patients reported no medical or surgical history.

\subsection{Quality Control of Identification}

The distribution of ultrasounds reports according to the quality control of identification was summarized in Table 2.

The analysis of the item identification of the patient was acceptable for surnames, given names and age. For the item Sonographer, it was acceptable for 
Table 2. Distribution of the ultrasound reports according to the identification $(n=200)$.

\begin{tabular}{|c|c|c|}
\hline Identification elements & Number & Percentage \% \\
\hline \multicolumn{3}{|l|}{ 1-Patient } \\
\hline \multicolumn{3}{|l|}{ Last Name } \\
\hline - Yes & 200 & 100.0 \\
\hline - No & 00 & 00.0 \\
\hline \multicolumn{3}{|l|}{ First Name } \\
\hline - Yes & 200 & 100.0 \\
\hline - No & 00 & 00.0 \\
\hline \multicolumn{3}{|l|}{ Age } \\
\hline - Yes & 136 & 68.0 \\
\hline - No & 64 & 32.0 \\
\hline \multicolumn{3}{|l|}{ 2-Sonographer } \\
\hline \multicolumn{3}{|l|}{ Last Name } \\
\hline - Yes & 180 & 90.0 \\
\hline - No & 20 & 10.0 \\
\hline \multicolumn{3}{|l|}{ First Name } \\
\hline - Yes & 180 & 90.0 \\
\hline - No & 20 & 10.0 \\
\hline \multicolumn{3}{|l|}{ Qualification } \\
\hline - Yes & 146 & 73.0 \\
\hline - No & 54 & 27.0 \\
\hline \multicolumn{3}{|l|}{ Adresse } \\
\hline - Yes & 94 & 47.0 \\
\hline - No & 86 & 43.0 \\
\hline \multicolumn{3}{|l|}{ 3-Ultrasound scanner } \\
\hline \multicolumn{3}{|l|}{ Date of start up } \\
\hline - Yes & 2 & 1.0 \\
\hline - No & 198 & 99.0 \\
\hline \multicolumn{3}{|l|}{ Brand Name } \\
\hline - Yes & 2 & 1.0 \\
\hline - No & 198 & 99.0 \\
\hline \multicolumn{3}{|l|}{ Type } \\
\hline - Yes & 4 & 23.0 \\
\hline - No & 196 & 98.0 \\
\hline
\end{tabular}

surname, first name, qualification and not acceptable for address (47\%). For the item Ultrasound scanner, it was not acceptable for the date of commissioning, brand and type ( $\leq 50 \%)$. 


\subsection{Quality Control of the Adequacy of the Appointment}

The distribution of ultrasound examinations according to the quality of the period during which they were performed has been presented in Table 3.

Only $48 \%$ of ultrasounds were performed in the ideal gestational interval 11 $14 \mathrm{GA}$. The quality of the implementation period was therefore not acceptable $(\leq 50 \%)$.

\subsection{Quality of the Iconography}

\section{Quantity of biometrics elements}

The distribution of the ultrasounds iconography according to the presence or not in the report in the various elements of biometry and dating has been presented in Table 4.

Biometric element information was mentioned in less than $50 \%$ of the cases for items such as BIP, nuchal translucency and number of required images. The quality of the biometry and dating was acceptable for the LCC and not acceptable for the BIP, the nuchal translucency (NT) and the number of images.

\section{Quality of the pictures supplied}

$\checkmark$ Nuchal translucency quality control (Herman's score)

- Major criteria of Herman's score

The distribution of ultrasounds according to the results of the assessment of Herman's major criteria has been presented in Table 5.

Out of 26 nuchal translucency clichés, the major criteria were observed in less than $50 \%$ for all the items. Compliance with the major criteria was of an unacceptable quality.

\section{- Herman's minor score criteria}

The distribution of ultrasounds according to the results of Herman's assessment of minor criteria has been presented in Table 6.

Out of 26 nuchal translucency clichés, minor criteria were observed in more than 50\% for amnion recognition (acceptable). For the zoom and the position of the head, it was respected in less than $50 \%$ of the cases (not acceptable).

\section{- Herman score results}

The results of the overall qualitative analysis of ultrasound scans according to Herman's criteria were represented in Table 7.

Of the 26 nuchal translucency images analyzed, nearly half were judged unacceptable by Herman's score.

Table 3. Distribution of ultrasound scans according to the period of it realization $(\mathrm{n}=$ 200).

\begin{tabular}{ccc}
\hline Period of implementation (GA) & Number & Percentage (\%) \\
\hline $11-14$ & 96 & 48.0 \\
$9-10$ & 30 & 15.0 \\
$6-8$ & 74 & 37.0 \\
Total & 200 & 100.0 \\
\hline
\end{tabular}


Table 4. Distribution of ultrasound scans according to the elements of biometrics recommended by the TCFE $(n=96)$.

\begin{tabular}{ccc}
\hline Biometrics elements & Number & Percentages (\%) \\
LCC & 64 & 66.7 \\
- Provided & 32 & 33.3 \\
- Not Provided & & \\
BIP & 44 & 45.8 \\
- Provided & 52 & 54.2 \\
- Not Provided & & \\
Nuchal translucency & 26 & 27.1 \\
- Provided & 70 & 72.9 \\
- Not Provided & & \\
The 3 pictures & 20 & 20.8 \\
- Provided & 76 & 79.2 \\
\hline
\end{tabular}

Table 5. Distribution of ultrasounds according to the results of the assessment of Herman's major criteria $(n=26)$.

\begin{tabular}{ccc}
\hline Elements of major criteria & Staff & Percentages (\%) \\
\hline Strict sagittal plan & 12 & 46.1 \\
- Yes & 14 & 53.8 \\
- No & & \\
Skin continuity & 8 & 30.8 \\
- Yes & 18 & 69.2 \\
- No & & \\
Calipers in place & 2 & 7.7 \\
- Yes & 24 & 92.3 \\
- No & & \\
\hline
\end{tabular}

Table 6. Distribution of ultrasounds according to the results of Herman's assessment of minor criteria $(n=26)$.

\begin{tabular}{ccc}
\hline Elements of minor criteria & Number & Percentage (\%) \\
\hline Sufficient zoom & 6 & 23.0 \\
- Yes & 20 & 76.9 \\
- No & & \\
Recognized or remote amnios & 16 & 61.5 \\
- Yes & 10 & 38.5 \\
- No & & \\
Neutral position of the head & 10 & 38.5 \\
- Yes & 16 & 61,5 \\
- No & & \\
\hline
\end{tabular}


Table 7. Frequency of Herman scores $(n=26)$.

\begin{tabular}{ccc}
\hline Scores & Frequencies & Percentages (\%) \\
\hline Unacceptable $(0$ et 1$)$ & 12 & 46.1 \\
Insufficient $(2$ et 3$)$ & 00 & 00.0 \\
Acceptable $(4-7)$ & 14 & 53.8 \\
Excellent $(>7)$ & 00 & 00.0 \\
Total & 26 & 100.0 \\
\hline
\end{tabular}

$\checkmark$ Quality control of biometry and dating by BIP and CCL

- The BIP

Table 8 shows the distribution of BIP cuts according to the recommended measurement parameters.

The analysis of the cuts showed that $77.3 \%$ of the BIP cuts are not of good quality. Therefore the quality of the BIP cuts is not acceptable.

\section{- The CCL}

The distribution of the CCL sections according to the recommended measurement parameters has been shown in Table 9.

Analysis of the cuts showed $85.4 \%$ of LCC cuts are not of good quality. Therefore the quality of LCC cuts is not acceptable.

\section{$\checkmark$ Quality control of early morphology}

The distribution of patients according to morphology analysis was presented in Table 10.

Information on morphological elements was not acceptable as it was mentioned in less than $50 \%$ of cases.

\section{Quality control of other elements of the report}

The results of the overall qualitative analysis of the ultrasounds according to the other morphological elements were represented in Table 11.

Information on the vitality elements of the embryonic and maternal appendices was acceptable as it was mentioned in more than $50 \%$ of cases.

\section{Discussion}

\subsection{Quality of the Period during Which Ultrasound Was Performed}

According to Coquel [1], screening ultrasound must be performed between 11 weeks of amenorrhea and 13 weeks +6 days of amenorrhea for several reasons including:

- Before 11 weeks, the measurement of the thickness of the NT is difficult because of the small size of the embryo.

- After 14SA, measurement is made difficult by the difficulty of obtaining in the same plane the cephalic pole and the trunk of the embryo.

- The choice of an upper limit of 13 weeks +6 days of amenorrhea also meets the need to be able to perform a medical interruption of pregnancy in the first trimester in case of pathology meeting the criteria of the law in force in the corresponding country. 
Table 8. Distribution of BIP cuts according to recommended measurement parameters ( $\mathrm{n}$ $=44)$.

\begin{tabular}{ccc}
\hline Benchmarks & Number & Percentage (\%) \\
\hline Axial plane & 44 & 100.0 \\
- Yes & 00 & 00.0 \\
- No & & \\
Symmetrical cut & 20 & 45.4 \\
- Yes & 24 & 54.6 \\
- No & & \\
Thalami and v3 visible & 15 & 34.1 \\
- Yes & 29 & 65.9 \\
- No & & \\
The 3 landmarks & 10 & 22.7 \\
- Yes & 34 & 77.3 \\
\hline
\end{tabular}

Table 9. Distribution of CCL cuts according to recommended measurement parameters $(\mathrm{n}=32)$.

\begin{tabular}{ccc}
\hline Benchmarks & Staff & Percentages (\%) \\
\hline Strict sagittal cuts & 10 & 33.3 \\
- Yes & 22 & 66.7 \\
- No & & \\
Calipers well placed & 9 & 28.6 \\
- Yes & 23 & 71.4 \\
- No & & \\
Head in neutral position & 8 & 23.8 \\
- Yes & 24 & 76.2 \\
- No & & \\
The 3 parameters & 5 & 14.6 \\
- Yes & 27 & 85.4 \\
\hline
\end{tabular}

Table 10. Distribution of patients according to morphology analysis $(n=96)$.

\begin{tabular}{lcc}
\hline Fetal morphology & Number & Percentage (\%) \\
\hline Appearance of the contour of the skull & & \\
- Yes & 4 & 4.2 \\
- No & 92 & 95.8 \\
Attendance of the four members & & 4.2 \\
- Yes & 4 & \\
\hline
\end{tabular}




\section{Continued}

$\begin{array}{lll}\text { - No } & 92 & 95.8\end{array}$

Four members each with 3 member segments

$\begin{array}{lcc}\text { - Yes } & 4 & 4.2 \\ \text { - No } & 92 & 95.8\end{array}$

Exploration of the anterior abdominal wall

$\begin{array}{lrc}\text { - Yes } & 4 & 4.2 \\ \text { - No } & 92 & 95.8\end{array}$

Exploring the centre line

$\begin{array}{ccc}\text { - Yes } & 2 & 2.1 \\ \text { - No } & 94 & 97.9\end{array}$

Table 11. Distribution of patients according to analysis of other morphology elements (n $=96$ ).

\begin{tabular}{|c|c|c|}
\hline Anatomical and functional structures & Number & Percentages (\%) \\
\hline \multirow{2}{*}{\multicolumn{3}{|c|}{$\begin{array}{c}\text { Vitality } \\
\text { Cardiac activity }\end{array}$}} \\
\hline & & \\
\hline - Yes & 92 & 95.8 \\
\hline - No & 4 & 4.2 \\
\hline \multicolumn{3}{|l|}{ Spontaneous mobility } \\
\hline - yes & 64 & 66.7 \\
\hline - No & 32 & 33.3 \\
\hline \multicolumn{3}{|l|}{ Heart Rate } \\
\hline - Yes & 50 & 58.1 \\
\hline - No & 46 & 47.9 \\
\hline \multicolumn{3}{|l|}{ Embryonic appendices } \\
\hline \multicolumn{3}{|l|}{ Appearance of the placenta } \\
\hline - Yes & 62 & 64.6 \\
\hline - No & 34 & 35.4 \\
\hline \multicolumn{3}{|l|}{ Amniotic volume } \\
\hline - Yes & 50 & 58.1 \\
\hline - No & 46 & 47.9 \\
\hline \multicolumn{3}{|l|}{ Exploring maternal appendices } \\
\hline - Yes & 74 & 77.1 \\
\hline - No & 22 & 22.9 \\
\hline
\end{tabular}

In our study, only $48 \%$ of ultrasounds were performed in the ideal gestational interval. The quality of the implementation period was therefore not acceptable. This result could be explained by the lack of rigour of the practitioners on the date of realization. In Cameroon Moifo et al. [6] found that only half (52.56\%) of 
sonographers knew the term for performing a systematic first trimester ultrasound. This result could also be explained by the failure to make an appointment; according to Salomon [7] the appointment is most often made according to the date of the last period announced by the patient. Sometimes the gestational age of 11 - 14 GA calculated with date of last menstruation (DLM) does not agree with an ultrasound age of 11 - 14 GA. Indeed in 2014 in Yaoundé, Ngowa et al. [8] had observed that among pregnant women who had performed a first trimester dating ultrasound, $42.70 \%$ had a theoretical gestational age and ultrasound discordance. Recall of DLM by memory, irregular cycle and doubt about reported DLM were factors significantly associated with theoretical and ultrasound gestational age discrepancy. Our results are close to those of Zoungrana [9] who had admitted at the end of his study that the majority of the first ultrasound examinations performed on pregnant women were mostly performed before $10 \mathrm{GA}$ and after $14 \mathrm{GA}$.

\subsection{Identification Control}

The latest generation cameras allow detailed morphological exploration through image quality and a reduction in the frequency of false positives and false negatives [10]. Of the 200 reports we studied, only 4 mentioned the type of aircraft and 2 mentioned the make and date of commissioning. Without this information we cannot judge the quality of ultrasound scanners. The results we obtained are not very acceptable and could be explained by the fact that the majority of ultrasound scanners used in our ultrasound rooms would be second-hand devices that do not have all the documents. This could also be explained by the possible existence of a fear of mentioning characteristics of a dilapidated ultrasound scanner. Indeed, Solomon said that an ultrasound machine older than 10 years should not be used in obstetrics because after this period it is no longer effective [7]. Our results are close to those of Zoungrana [9] who obtained only $9.47 \%$ for the make of the device and $0.00 \%$ for the type and the date of activation of the device.

\subsection{Quality of the Iconography}

\section{$\checkmark$ Quantity control}

An acceptable proportion of ultrasounds had provided CCL (66.7\%) but the proportion of ultrasounds that had provided BIP and NT was not acceptable at 45.8\% and 27.1\% respectively. Benacerraf [11] and Mavrides [12] felt that nuchal translucency measurement should be systematic in the first trimester because it can be associated with a number of heart and karyotype abnormalities. The explanation of this low NT measurement rate could be found in the fact that the measurement of the NT thickness requires the use of recent ultrasound scanners presenting on the one hand the ciné-loop function and on the other hand a resolution of the measuring calipers of the order of $1 / 10$ of $\mathrm{mm}$ [13]. Most medical facilities would not have. Even if we are dissatisfied with the results we note that 
there is progress in our country because Zoungrana [9] in 2012 had found no measure of nuchal translucency in 117 reports he had studied. The proportion of ultrasound scans that had provided the 3 images recommended by the National Technical Committee for Prenatal Screening Ultrasound was not acceptable (20.8\%). This may be due to the fact that many sonographers place little importance on the number of images to be provided in the first trimester screening ultrasound iconography. Moifo et al. [6] in Cameroon found that only $8.97 \%$ of sonographers cited all of the mandatory images to be included in the report.

\section{- Quality control}

\section{$\checkmark$ Nuchal translucency}

After evaluation of the 26 nuchal translucency clichés we realized that the proportion of clichés of "unacceptable" quality i.e. with a score of Herman $<2$ was $41.67 \%$. The non-application of the measurement criteria by sonographers could explain our figures. Moifo et al. [6] had interviewed 78 sonographers, of whom only 18 , or $23.7 \%$ of the participants, had cited all the criteria for good nuchal translucency measurement. In the United Kingdom, in 2008, the learned society United Kingdom association of sonographers (UKAS) [14] recommended durations of obstetrical ultrasound in a quality approach aimed at "taking biometric measurements correctly and not omitting detection of an abnormality". These measures do not exist in our country and this could explain the high proportion of unacceptable measures of the quality of NT measures that we analyzed. The proportion of "acceptable" quality shots was $58.33 \%$, that of "excellent" quality shots $00 \%$. These results are significantly lower than those of Labarrere [15] which obtained in 2011 a rate of $71.2 \%$ for acceptable clichés and a rate of $25.6 \%$ for excellent clichés. This difference could be explained by the fact that in France, the decree of June 23, 2009, which specifies the methods of prenatal screening, guides ultrasound specialists in their practice [16].

\section{$\checkmark$ Quality control of dating and biometrics by CCL and BIP}

Analysis of the 32 cranio-caudal length measurements showed that $33.33 \%$ of the cuts were made on a strict sagittal plane. Fetal head was neutral in $23.81 \%$ and calipers were well placed in $28.57 \%$ of cases. Therefore among 48 CCL images, only 14 cuts were of good quality (14.58\%). We are not satisfied because the NT cannot be interpreted without a good CCL. It has been shown that the threshold used for the definition of nuchal hyperclarity is not fixed and varies according to the CCL [17]. The CCL is also an important parameter of biometrics and dating. In the study population of Moifo et al. [6] the CCL was recognized as a reliable parameter for dating for $74.3 \%$ of the participants, but the criteria for its realization were taken into account by only $39.76 \%$ of the participants. There is therefore a disconnection between knowledge of the importance of the CCL and knowledge of its benchmarks. This study could explain our results because $68 \%$ of the provided the CCL but only $14.58 \%$ of the LCCs had been carried out using the above-mentioned benchmarks correctly. Analysis of the 44 BIP cuts revealed that only 10 BIP cuts were of good quality. Conse- 
quently, the quality of the BIP cuts was not very acceptable. This result is more than unsatisfactory because from 12 - 13 SA, the CCL becomes less precise and the measurement of the biparietal diameter appears more efficient for dating [13].

\section{$\checkmark$ Quality early morphology}

This is the role of the very first morphological examination that has focused all the attention of ultrasound specialists on the first trimester ultrasound over the past five years. This examination makes it possible to diagnose acrania, abdominal wall abnormalities and many lethal forms of malformative syndrome at this term [1]. Even if ultrasound does not detect all morphological anomalies, it allows an early diagnosis of those that are major [18]. Despite the importance of the morphological study of the fetus, we found that among the reports we studied, sonographers had almost no importance to the different elements of the foetal morphology with a rate of $4.26 \%$ (i.e. 4 reports) for the appearance of the contour of the box, the presence of the 4 limbs each comprising 3 limb segments and the exploration of the anterior abdominal wall. And finally, $2.26 \%$ (2 reports) for the exploration of the median line. We can conclude that in our study no element of morphology was explored at an acceptable proportion. In many reports, it was mentioned that fetal morphology was "normal", a statement that we did not consider because summarizing it in this way does not describe morphology. That fact could explain our results. These results are alarming because they indicate a significant drop in rates. Indeed, in 2012 in Zoungrana's study [9], morphology was represented in $26.50 \%$ of the reports. A study conducted by Moifo and colleagues [6] in Cameroon among sonographers showed that the morphological study was systematic for only $47.4 \%$ of the sonographers. This indicates a lack of interest in the study of fetal morphology, which may explain our results.

\section{Conclusion}

The results revealed the acceptable quality of the NT measurements, but a small proportion of NT achieved. Our study also revealed the unacceptable quality of the ultrasound, morphological analysis and biometrics period. At the end of our work new questions appear, why is there a significant gap between the observed quality of ultrasound and that prescribed by the literature? What may be the impact on the prognosis of pregnancy?

\section{Conflicts of Interest}

The authors declare no conflicts of interest regarding the publication of this paper.

\section{References}

[1] Coquel, P., Bault, J.-P. and City, Y. (2010) Obstetrical Ultrasound in the First Trimester. Medical Sauramps, Montpellier. 
[2] Economides, D.L. and Braithwaite, J.M. (1998) First Trimester Ultrasonographic Diagnosis of Fetal Structural Abnormalities in a Lowrisk Population. British Journal of Obstetrics and Gynaecology, 105, 53-57. https://doi.org/10.1111/j.1471-0528.1998.tb09350.x

[3] Economides, D.L., Whitlow, B.J. and Braithwaite, J.M. (1999) Ultrasonography in the Detection of Fetal Anomalies in Early Pregnancy. British Journal of Obstetrics and Gynaecology, 106, 516-523. https://doi.org/10.1111/j.1471-0528.1999.tb08317.x

[4] Salomon, L.J. and Bault, J.-P. (2010) Dating and Biometrics. Obstetrical Ultrasound in the First Trimester. 2nd Edition, Sauramps medical, Paris.

[5] Salomon, L.-J., Bernard, J.-P. and City, Y. (2004) First Trimester Ultrasound Should Be a Tailored Examination. Journal de Gynécologie Obstétrique et Biologie de la Reproduction, 33, 375-377. https://doi.org/10.1016/S0368-2315(04)96543-X

[6] Moifo, B., Dzeukam, A., Tebere, H., Foumane, P., Tambe, J. and Gonsu, J. (2012) Evaluation of Knowledge and Practical Attitudes in Systematic Ultrasound of the First Trimester of Pregnancy in Cameroon. Medical Thesis, Faculty of Medical and Biological Sciences, Yaoundé.

[7] Salomon, L.J. (2010) Quality Control. Obstetrical Ultrasound in the First Trimester. 2nd Edition, Editions Sauramps médical, Paris, 279.

[8] Ngowa, J., Mando, E., Guegang, E., Ngassam, A. and Kasia, J. (2014) Dating of Pregnancy in Current Practice in Cameroon: Reliability of the Date of Last Menstruation. The Pan African Medical Journal, 17, 264.

http://www.panafrican-med-journal.com/content/article/17/264/full/

[9] Gillet, J.Y., Boog, G., Dumez, Y., Nissand, I. and Vallette, C. (1990) Ultrasound of Fetal Malformations. VIGOT Edition.

[10] Zoungrana, I. (2012) Audit of Ultrasounds of the First Trimester of Pregnancy; About 117 Reports Colleges in Four (04) Health Structures in Ouagadougou. Medical Thesis, Faculty of Health Sciences, Ouagadougou.

[11] Benacerraf, B.R., Neuberg, D., Bromley, B. and Frigoletto, F.D. (1992) Sonographic Scoring Index for Prenatal Detection of Chromosomal Abnormalities. Journal of Ultrasound in Medicine: Official Journal of the American Institute of Ultrasound in Medicine, 11, 449-458. https://doi.org/10.7863/jum.1992.11.9.449

[12] Mavrides, E., Cobian-Sanchez, F., Tekay, A., Moscoso, G. and Campbell, S. (2001) Limitative of Using First Trimester Nuchal Translucency in Screening for Major Congenital Heart Defects. Ultrasound in Obstetrics \& Gynecology, 17, 106-110.

[13] Quarello, E., Ville, Y. and Bault, J.-P. (2010) Clarity of the Neck. Obstetrical Ultrasound in the First Trimester. 2nd Edition, Sauramps medical, Montpellier, 279.

[14] United Kingdom Association of Sonographers (2008) Guidelines for Professional Working Standards: Ultrasound Pratice. UKAS.

[15] Labarrere, A. (2012) Evaluation of the Quality of the First Trimester Ultrasound before and after the Application of the Decree of 23 June 2009. Medical Thesis, University of Poitiers, Poitiers.

[16] Ministry of Health and Sports (2009) Ministry of Health and Sports Order of 23 June 2009.

[17] Schwärzler, P., Carvalho, J.S., Senat, M.V., Masroor, T., Campbell, S. and City, Y. (1999) Screening for Fetal Aneuploidies and Fetal Cardiac Abnormalities by Nuchal Translucency Thickness Measurement at 10 - 14 Weeks of Gestation as Part of Routine Antenatal Care in an Unselected Population. British Journal of Obstetrics and Gynaecology, 106, 1029-1034. https://doi.org/10.1111/j.1471-0528.1999.tb08109.x 
[18] Snijders, R.J., Johnson, S., Sebire, N.J., Noble, P.L. and Nicolaides, K.H. (1996) First-Trimester Ultrasound Screening for Chromosomal Defects. Ultrasound in Obstetrics \& Gynecology, 7, 216-226.

https://doi.org/10.1046/j.1469-0705.1996.07030216.x 